Addressing food insecurity in college:

\title{
Mapping a shared conceptual framework for campus pantries in Michigan
}

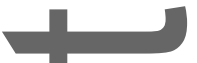

Abstract

The first known university food pantry started at Michigan State University in 1993 (Saul, 2016).

Since then, campus food pantries are more widespread, although little is known about them (Kovacs, 2016). The current study examined how college pantries best serve students and foster their success.

Twenty-eight food pantry directors and staff from across sixteen Michigan college campuses engaged in concept mapping, a technique used to examine the interrelationships among concepts understood (1)

by stakeholders. Analyses identified six concepts, examined importance of each concept as assigned

by participants, and evaluated variation among institutions. Implications for findings and future research directions are discussed.

Keywords

College campus food pantries, Concept mapping, Food insecure college students, Food insecurity Food insecurity among US households is a growing issue, and especially prevalent among college students (Coleman-Jensen, Rabbitt, Gregory, \& Singh, 2016; Goldrick-Rab, Broton, \& Eisenberg, 2015). To address student hunger, colleges and universities across the nation have developed food pantries (College and University Food Bank Alliance [CUFBA], 2017). These pantries are often initiated by faculty and staff in response to concerns that students are, for example, skipping meals and making difficult choices between whether to buy books or food (Dubick, Mathews, \& Cady, 2016). As each campus pantry is developed in response to concerns of food insecurity among college students on their respective campuses, the pantries are siloes functioning separately (CUFBA, 2017).

Little is known about college campus food pantries' operations and goals. Increased knowledge about

This is the ant r manuscript accepted for publication and has undergone full peer review but has not been thi woh th copyediting, typesetting, pagination and proofreading process, which may lead to differences betr this version and the Version of Record. Please cite this article as doi: 10.1111/asap.12161.

This article is protected by copyright. All rights reserved. 
campus food pantries has the potential to facilitate coordinated efforts to address student food insecurity. The current research study sought to foster dialogue between campus food pantry representatives for one day in order to understand more about their current and envisioned support of food insecure college students. The First Annual Michigan College Campuses Food Pantry Summit was held in October of 2016 in an effort to bring food pantry administrators and staff together to discuss their campuses pantries and ascertain commonalities in how they believe the pantries help students' academic success. This was achieved through the facilitation of a concept mapping workshop.

\section{Literature Review}

Across the United States, an increasing number of households are experiencing food insecurity. Food insecurity is defined by the United States Department of Agriculture as having "limited or uncertain access to nutritious, safe foods necessary to lead a healthy lifestyle. Households that experience food insecurity have reduced quality or variety of meals and may have irregular food intake" (USDA, 2016). Approximately 13 percent of households in the United States were food insecure in 2015 (Coleman-Jensen et al., 2016). Of those experiencing food insecurity, 5 percent were experiencing 'very low' food security (Coleman-Jensen et al., 2016). Very low food security is a classification used when one or more members of a household go hungry because of insufficient money to purchase food. The severity of food insecurity varies among states. In Michigan, food insecurity rates are slightly higher than national averages. Approximately 1 in 7 (14.7\%) Michigan households are food insecure (Tanner, 2015).

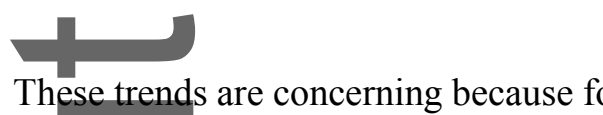

Food insecurity is linked with poor diet, obesity, high blood pressure, stress, difficulty concentrating, and persistent worry (Seligman, 2016). It also impacts the choices households are able to make. When households are food insecure, they often have to choose between food and household utilities, transportation, housing, or even medication (Feeding America, 2014).

This article is protected by copyright. All rights reserved. 
Food insecurity is increasing across the nation, and higher rates are found among adults in college than in the general population. A national survey of 4,000 undergraduates at ten community colleges across the US found that half of the students were struggling with food insecurity (Goldrick-Rab et al., 2015). This has led several two- and four-year colleges to track food insecurity on their campuses. For example, a study across the ten-campus University of California system found that 19 percent of students self-identified as having 'very low' food security and an additional 23 percent responded as having 'low' food security (Martinez, Maynard, \& Ritchie, 2016). More than half (57\%) of the 8,923 undergraduate and graduate UC students surveyed said that they were new to food insecurity (Martinez et al., 2016). The City University of New York found that 39.2 percent of students reported food insecurity, with 22.7 percent also reporting going hungry (Freudenberg, Manzo, Jones, Kwan, Tsui, \& Gagnon, 2011). Researchers at the University of Hawai'i, Manoa found that 21 percent of undergraduate students were food insecure (Chaparro, Zaghloul, Holck, \& Dobbs, 2009). Additionally, universities in Oregon, Alaska, and Maryland found that half or more of the college students on these campuses reported food insecurity in the past year (Lindsley \& King, 2014; Maroro, Snelling, \& Linek, 2015; Patton-Lopez, Lopez-Cevallos, Cancel-Tirado, Vasquez, 2014). Particular groups of college students are disproportionately affected by food insecurity. College students who live alone, are single parents, students of color, and those who rely on Pell Grants are more likely to be food insecure (Maroto, Snelling, \& Linck, 2015; Twill, Bergdahl, \& Fensler, 2016). Overall, these studies find a positive correlation between the students who are most at risk for economic hardship and those most likely to use campus food pantries.

There are few resources available for college students that face economic challenges, such as those that underlie food insecurity. The United States Department of Education distributes the Federal Pell Grant Program, which provides needs based grants to low-income undergraduate students for twelve semesters of higher education (United States Department of Education [USDE], n.d.). The maximum Pell Grant award for the 2016-2017 academic year was \$5,815 (USDE, n.d.), yet the 
national average cost to attend a public four-year university during the 2016-2017 academic year was $\$ 8,940$ (College Board, 2017). Federal and state funding of higher education was greatly diminished during the 2009 recession and has not been restored (Mitchell, Leachman, \& Masterson, 2016). These cuts have had immediate consequences for students, including increased tuition costs and diminished student services (Mitchell et al., 2016).

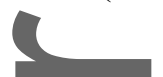

In the wake of decreased state and federal financial support of higher education, increased tuition, and heightened food insecurity, colleges and universities have started to develop campus food pantries. College campus food pantries are designed to help low-income students who are struggling D with food insecurity (Jordan, 2015; Mitchell et al., 2016). Over the last decade, there has been a proliferation of food pantries on campuses. According to the College and University Food Bank Alliance (2017), there was one known college campus food pantry in 2007 and by 2017 there were more than five hundred registered members. Although there has been some documentation of rates of food insecurity among college students, little is known about college and university food pantries themselves. How are service providers navigating student needs? What does success look like to college campus food pantries?
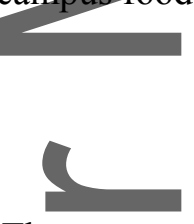

\section{Purpose of the Study}

The purpose of this study is to better understand the role of college food pantries on campuses. Specifically, how do campus food pantries currently and ideally serve students to foster their success? To answer this research question, data from a concept mapping activity conducted in October 2016 are analyzed and reported.

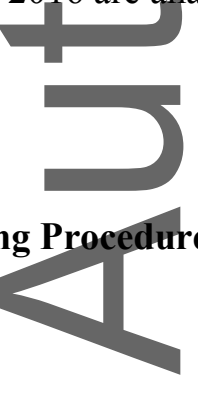

Sampling Procedures and Participants

Method

This article is protected by copyright. All rights reserved. 
Invitations were sent to pantry directors at university campuses that were within 3 hours driving distance of the University of Michigan, Dearborn. Twenty-eight food pantry directors, faculty, and staff from sixteen universities and colleges from across Michigan participated in the Michigan College Campuses Food Pantry Summit held in October 2016. The participants represented food pantries at community colleges ( 2 year, $n=9,32 \%$ ) and universities (4 year, $n=19,68 \%$ ), which included undergraduate-only $(n=16,57 \%)$ and undergraduate and graduate $(n=12,43 \%)$ serving institutions. Participants encompassed different roles in their campus food pantries, with some administrators/directors $(n=6,21 \%)$, faculty $(n=5,18 \%)$, staff $(n=8,28.5 \%)$, student volunteers $(n$ $=4,14.5 \%)$, and a few who designated themselves as "other" $(n=5,18 \%)$. A little more than half of the participants had worked at their campus food pantry for less than one year ( 0 -11 months, $n=14$, $50 \%$ ), while the other half had worked at their campus food pantry for one or more years (1-3 years, $n$ $=11,39 \% ; 4-6$ years, $n=2,7 \% ; 6+$ years, $n=1,4 \%)$. The majority of the college food pantries had been in operation for less than three years ( $0-11$ months, $n=9,32 \% ; 1-3$ years, $n=12,43 \%)$ and the remainder for more than four years (4-6 years, $n=3,11 \% ; 6+$ years, $n=4,14 \%)$. The majority of participants self-identified as female ( $n=24,88 \%$; male, $n=4,12 \%)$ and European American/White ( $n=24,86 \%$; African American/Black, $n=2,7 \%$; Asian American/Pacific Islander, $n=1,3.5 \%$; Latin@/Hispanic, $n=1,3.5 \%$ ). See Table 1 for demographic information. Each campus was offered $\$ 150$ to compensate for their time and travel expenses.

\section{Research Design and Data Analysis}

Concept mapping is a stepwise process in which participants collaborate to identify a shared framework about a topic of interest (Campbell \& Salem, 1999; Davies, 2011; Jackson \& Trochim, 2002; Kane \& Trochim, 2007; Wheeldon \& Faubert, 2009; Windsor, 2013). Five steps were utilized in this applied research method. Step one involved determining the research question and sample. The research question for this study was: How does your campus pantry best serve students and foster their success?

This article is protected by copyright. All rights reserved. 
In step two, participants brainstormed answers to the research question. At this stage, stakeholders worked individually on tablets to generate short qualitative statements, providing their knowledge-and opinions about how their campus pantry best serves students and fosters their success. Their responses were anonymously compiled in the online concept-mapping software, The Concept System ${ }^{\circledR}$ Global MAXTM. As the participants worked through this step, the research team answered participants questions about the software and tablets. It took the participants just over 40 minutes to complete this step. The responses generated a list of over 250 statements.

In the third step, researchers synthesized the qualitative data gathered during brainstorming to reduce redundancy and enhance concept consolidation. The researchers eliminated redundant statements and separated longer statements into multiple shorter statements while preserving the integrity of the information provided. This process produced a final, more parsimonious set of 113 independent statements.

In step four, known as structuring the statements, participants individually performed two tasks: sorting and rating. The sorting and rating of the final statement set was a conceptual process that relied-on participants' perception of the relationship between the statements and the value that they attached to each statement. In the first task, participants sorted the statements into piles or clusters composed of similar ideas to form distinct conceptual groupings. Due to randomization, all participants saw the same statements but in a different order. Each statement could only be placed into one cluster, thereby compelling the stakeholders to make choices. Once a statement was added to a cluster it automatically disappeared from the list of statements that needed to be sorted. In this way, the participants were able to monitor their progress as they advanced through the task. Participants labeled each cluster that they developed. The process took approximately 45 minutes. Twenty-eight participants began the sorting phase and 28 finished the task. Once sorting was complete, the participants worked individually on the rating task, assigning a measurable value to each statement. Using a Likert-type scale, participants rated each statement on three dimensions: (1) importance $(1=$ 
not very important to $5=$ extremely important $),(2)$ effect on student success $(1=$ no effect to $5=$ major effect), and (3) level of difficulty $(1=$ very difficult to $5=$ very easy). It took participants approximately one hour to rate the final statements and the attrition rate varied by each dimension: 28 participants started to rate the importance of each statement and 24 finished; 18 participants started to rate the effect on student success and 12 finished; 13 participants started to rate the level of difficulty and 11 finished.

In step five, the concept mapping analysis, the arithmetic mean of the ratings is computed to create a multi-dimensional analysis of each statement and cluster maps of the emergent concepts. In preparation for the analysis, the sorting and rating data was checked for completion and quality. First, sorting data was analyzed for variation in participants' development of concepts. Participants' ratings were then examined. Researchers looked for patterns such as rating all statements important or rating the first five statements as $1,2,3,4,5$ and then repeating that on the next five statements. No obvious patterns emerged from the raw data. This indicated that all participants who finished provided meaningful ratings. Although the majority of participants completed the importance ratings, fewer than half the participants finished rating the effect on student success and level of difficulty, therefore there was not enough data to provide a meaningful analysis. As such, these two rating categories were not analyzed.

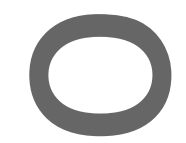

\section{Results}

There are four interdependent stages of analysis. The first is the Point Map, which shows the distribution of various statements generated by participants with no numeric value attached to each (1) statement and shows how the themes emerged in various quadrants of the map. The Point Map shows the interconnections between different statements and helps in determining the number of conceptual clusters. The second analysis is the Concept Map, which is used to further refine the concepts into a more parsimonious conceptual map of the data. The third analysis is of the rating data to generate the Cluster-Rating Map. This map shows cluster averages based on the relative ratings assigned by the 
stakeholders. The final analysis is the Pattern Match Maps, which is utilized to examine how concepts were prioritized based on demographic comparisons and correlation coefficients. The following subsections present each map and the associated findings.

Point Map

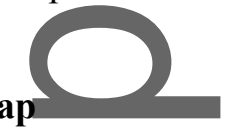

The point map, which is the first analysis to be run, shows the relationship between each statement based on the participants' sorting data. The point map is a relational map that shows statements in terms of their proximal relationship to one another. Statements that are depicted in close proximity to one another on the point map were more frequently sorted together than the statements that are farther apart. Statements on the edge of the point map were more frequently sorted with fewer other statements. Statements in the middle of the map represent broader ideas, as they are balancing relationships with many areas of the map. The clustering of statements on the point map indicates the emergence of discrete themes. Six or seven concept clusters are visible in the different quadrants of the point map (see Figure 1).

\section{Cluster Map}

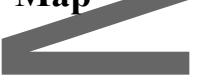

To examine the themes that emerged, the software assembles cluster maps. Cluster maps were created in configurations of five, six, and seven clusters. Maps were carefully examined for the proximity of the clusters to one another. The clusters that are closer together are more related to one another than those that are farther apart. The two lead authors examined the consistency of statements in each cluster to see if similar conceptual patterns emerged, and noted when overlap between clustered concepts 0 ccurred. Overlapping cluster concepts were pared down to create a more parsimonious cluster map.

Upon narrowing the clusters, the researchers arrived at consensus that the six-cluster configuration captured the most amount of data in a meaningful way. The cluster map displays the macro-level view of the conceptual groupings. The concept clusters generated by the participants 
were: (1) Accessibility, (2) Available Items, (3) Student Success, (4) Support, (5) Partnerships, and

(6) Awareness (see Figure 2). The labels were generated from the most common labels participants used to name their sorted piles. For a full list of clusters and the items within each cluster, see Table 2 .

The first cluster, Accessibility, contained statements that pertained to rules for usage, the pantry intake process, frequency of use by student-clients, eligibility criteria, and client confidentiality. Sample items from this cluster include: (1) "We do not ask our students to provide any type of financial evidence' as to their need," (2) "We treat students with respect with a 'no questions asked' approach other than verifying student status and basic assessment questions," (3) "The pantry is confidential and respectful," (4) "We are working on measures to make the intake form electronic, 'hassle-free' and connected to our student information database," and (5) "We open Monday - Friday with a good amount of hours each day so there is a lot of availability for them." Overall, the Accessibility cluster is concerned with the students' themselves and their experiences with the food pantry.

The second cluster, Available Items, contained statements about household and food needs, pantry services, understanding needs, and items offered. Sample statements from this category include: (1) "[We] provide necessary hygiene supplies to students in need," (2) "We offer food they can eat white on campus so they can focus on school not their hunger during class," (3) "We want to provide options for everyone," (4) "Provide healthy alternatives to what students can afford to buy," and (5) "Our goal is to provide as many students as possible with a variety of food items with an increased emphasis on fresh fruits and vegetables." The Available Items concept cluster is primarily concerned with the type and variety of food and households items available to food insecure college students.

While the first two clusters were concerned with students' ability to access the pantry and the availability of food items, the third cluster centered on what participants labeled Student Success. This cluster contained statements related to holistic student support, including academic support, student 
retention, academic success, easing stress, and reducing anxiety. Sample statements in the third cluster are: (1) "It's more than just about academics regarding the lives of students," (2) "I hope the pantry will assist students in meeting their basic needs as part of a larger program focusing on non academic needs such as homelessness, food insecurity, accessing health care, etc," (3) "Remove stress that comes from experiencing food insecurity," (4) "I feel students can not be successful academically to their full ability if they have to worry about where their next meal is coming from," and (5) "By providing food to students to fill their stomachs to promote academic success." Broadly, the Student Success concept centers on the physical and psychological needs of food insecure students.

Related to fostering student success in cluster three, the fourth concept group was labeled Support and contained items relevant to evaluation/assessment of students' needs, information on supplemental programs, and the referral of students to additional resources off campus. Sample statements from this concept cluster include: (1) "Have the ability to help students apply for SNAP," (2) "We also have numerous food drives throughout the year," (3) "Provide nutrition education," (4) "We offer-referral services to community based agencies to assist with any other problems that the student may be facing," and (5) "Hope to provide financial literacy workshops." In short, the Support cluster is comprised of items related to helping students apply for and receive help from off-campus programs.

The fifth concept grouping moved beyond the college campus environment to address Partnerships with the broader community. The Partnership cluster contained statements about financial support, networking, campus-community partnerships, and creating a more robust culture of care. Sample items from the partnership cluster include: (1) "We dream that our pantry will partner with Michigan Department of Health and Human Services to offer more efficient paperwork processing for Women Infant and Children/Supplemental Nutritional Assistance Program/Food Stamp assistance," (2) "Create a community service project for students that don't need access to a food pantry," (3) "Increase community outreach work towards sustainability," (4) “As a newer initiative we This article is protected by copyright. All rights reserved. 
are still working on assessment practices to determine how we are impacting student retention and progress to degree completion," and (5) "We dream to partner with universities across MI to start a statewide initiative to remove barriers for our students." The Partnership cluster involves the food pantries themselves and their relationships with other non-campus organization to help address oncampus student needs.

(

The sixth conceptual cluster, which participants labeled Awareness, contained statements related to information dissemination and educational campaigns on and off campus and raising awareness among faculty, staff, and campus administrators. Sample statements from this cluster include: (1) "Inerease awareness about the pantry among faculty and staff," (2) "Create a culture of care at the university where we don't hide from challenges but face them together," (3) "We dream to raise awareness about food insecurity across campus and within our community," (4) "Create visibility of a problem that a lot of people don't know exists," and (5) "Once awareness of pantry services are accomplished, serving the community at large is less of a challenge." In general, the Awareness eluster focused on information and education about food insecurity to the broader campus.

Overall, these findings reveal interesting patterns. There were two concepts concerned with the students themselves, Accessibility and Student Success. These conceptual clusters were centered on viewing students' lives as interconnected, the belief that their food insecurity was also related to their academic success and retention, as well as attention to maintaining students' confidentiality while accessing the pantry. Other concepts, such as Available Items and Support, were connected with maintaining a variety of available household and food items, in addition to interest in assessing other student needs and flexibility in the creation of supplemental programs to meet additional necessities. The final two concepts, Partnerships and Awareness, contained elements of networking both on and off campus. While the concept cluster map provides insights into the components of each concept, the importance of each cluster to the pantries ability to serve students and foster their success may vary. To examine the influence of each cluster on food pantry success, cluster-rating maps were analyzed. 


\section{Cluster-Rating Map}

The cluster-rating map is used to examine the relative importance of statements within each cluster to provide information about the overall importance of each cluster on how campus pantries best serve students and foster their success. The number of layers for each cluster corresponds to the level of importance. The clusters with more layers have higher average ratings (Figure 3. ClusterRating Map by Importance).

Using a 5-point Likert type scale with $1=$ not very important to 5 = extremely important, participants $(n=25)$ rated each statement by perceived level of importance to the research question: How does your campus pantry best serve students and foster their success? Each cluster had an average importance rating, with higher ratings equating to more perceived importance: (1) Accessibility cluster had an average importance rating of $M=3.75$; (2) Available Items, $M=4.27$; (3) Student Success, $M=4.35$; (4) Support, $M=3.84$; (5) Partnerships, $M=4.10$; and (6) Awareness, $M$ $=4.33$. Overall, these averages indicate that participants rated Student Success of their food pantry as the most important, followed by Awareness, Available Items, Partnerships, Support, and Accessibility as less important. To examine the potential differential importance each conceptual cluster has on food pantry success, demographic specific pattern match maps were analyzed.

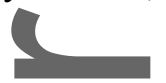

\section{Pattern Match Maps}

Pattern match maps provide information about how sets of participant ratings compare with each other. For the current study, pattern match maps were used to examine the variation in the importanee ratings of the concept clusters by demographic information. We ran three pattern match maps to examine the difference in importance by school type, length of pantry operation, and type of students served to gain a more nuanced understanding of what college campus pantries see as important to their success.

This article is protected by copyright. All rights reserved. 
The first pattern match map examines the importance of the different concept clusters based on the type of school, comparing the perceptions of food pantry directors and staff at two-year community colleges versus four-year universities (see figure 4). The figure shows a moderately strong relationship between the two groups' ratings across nearly all of the clusters, particularly between the relative cluster ratings and overall Pearson product moment correlational value $(\mathrm{r}=0.57)$. Specific areas of agreement about cluster importance are the concepts of Support and Accessibility. Areas where the directors and staff at two-year colleges and four- year universities diverged in ratings of importance ean be seen in Partnerships, Student Success, and Available Items. Specifically, directors and staff at two-year colleges rated Partnerships with community resources and Awareness of food insecurity among college students as more important than did those at four-year universities. In contrast, direetors and staff at four-year universities rated Student Success and Available Items as more important to the overall success of the campus food pantry than did those at two-year colleges.

Pattern matching results were also generated for the importance of concepts by length of food pantry operation. Specifically, we were interested in understanding how the length of time a pantry was in operation affected what was considered important to the success of the food pantry. Pantries that have been in operation for less than three years were compared to those that have been in operation for four or more years. The perceived importance of each cluster to student success varied by length of pantry operation; figure 5 shows a fairly strong relationship $(r=0.74)$. A closer look at variation among pantry operating time shows that for college pantries that have been operating for less than three years, Student Success, Available Items, and Support were rated as more important than they were for pantries in operation for four or more years. For pantries that have been in operation longer, Awareness and Accessibility were rated as more important than newer pantries. Pantries operating less than three years and those operating four or more years both ranked Partnerships of similar importance.

This article is protected by copyright. All rights reserved. 
The final pattern match analysis compared the average cluster rating by directors and staff at undergraduate-only institutions versus universities that serve undergraduate and graduate students. Figure 6 shows that there is a strong relationship between the type of institution and the importance of different dimensions for food pantry success $(\mathrm{r}=.83)$. For undergraduate-only colleges, Awareness and Partnerships were rated more highly than they were for institutions with both undergraduate and graduate students. At campuses serving both undergraduate and graduate students, Student Success and Available Items were rated more highly. There was no difference in the importance ratings of Accessibility, which was the lowest rated issue for directors, staff, and volunteers at both undergraduate-only and graduate serving institutions.

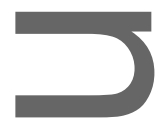

\section{Discussion}

Concept mapping was utilized to examine the meanings of food pantry success provided by college campus food pantry directors, staff, and volunteers. Food pantry stakeholders shared six concepts for determining success in meeting the needs of food insecure college students. The concept map showed that campus food pantries are concerned with addressing students' needs at different levels, moving from individual to interpersonal to institutional. Starting with the students themselves, at the individual level, the Accessibility and Student Success clusters were concerned with the presence and effects of food insecurity in students' lives. At the interpersonal level, the campus food pantry stakeholders identified Partnerships and Awareness as important to fostering on-campus awareness of and commitment to addressing food insecurity and expanding to an off-campus community of networks for student referrals and support. Finally, at the institutional level, the campus food pantry participants identified Available Items and Support, that is, having a variety of items available and flexibility in organizational arrangements and goals to meet needs as important to the success of their pantries. Collectively, the conceptual clusters illustrate the complexity of multi-level factors in the success of meeting food insecure students' needs. 
Concepts took on differential importance between the campuses. The pattern match maps show the different weight campuses gave to each of the conceptual clusters. For two-year colleges, pantries operating longer than four years, and undergraduate-only institutions were more likely to cite Awareness of food insecurity as important to the success of their pantry, indicating that perhaps campus outreach is important for campuses that meet this demographic criteria. Another important finding from the pattern match maps was that Student Success and Available Items hung together as the most important clusters for four-year universities, pantries operating for less than three years, and campuses serving undergraduate and graduate students. This indicates that for newer campus pantries located at universities requiring longer-term attendance from bachelor and masters students that a holistic understanding of students' needs and lives is closely related to having a variety of household and food related items available in pantries. The importance of clusters depending upon institution types, students served, and length of pantry operation provides direction to campus food pantry development and may serve to help established pantries improve services.

To date, there is very limited research on college food pantries themselves. Therefore, this study has important implications for guiding program development. Specifically, knowing more about the importance of each conceptual element, and the role it plays in the success of the campus pantries, helps other campuses interested in developing a pantry think about areas they may want to focus their efforts. In an effort to facilitate communication between pantries and the understanding of shared importance, the concept maps and findings were distributed to the campus food pantries through a technical report (Sampson, Al-Khshali, Reppond, Price, \& Thomas-Brown, 2017). Additionally, the findings may be valuable to college administrators interested in supporting existing pantries or helping staff develop a food pantry on their campus.

While there are important implications, there are also several limitations to this study. Participant attrition may have been caused, in part, by technological limitations, as several participants expressed frustration with using their tablets. Another likely contributor to the attrition 
during the rating portion of the study was fatigue. Several participants expressed that they were tired after the importance-rating task. One solution would have been to provide more frequent breaks between the ratings tasks.

Another limitation of the study was that there was not enough time in the day to have a substantive conversation with the food pantry stakeholders about the concepts that emerged from their data. This conversation may have provided more discussion allowing more comprehensive interpretation of the results and mutual feedback between participants on the implications of this research for their pantries.

\section{Conclusion}

While food insecurity among college students has been established (Chaparro, Zaghloul, Holck, \& Dobbs, 2009; Freudenberg, Manzo, Jones, Kwan, Tsui, \& Gagnon, 2011; Goldrick-Rab et al., 2015; Lindsley \& King, 2014; Maroro, Snelling, \& Linck, 2015; Martinez, Maynard, \& Ritchie, 2016; Patton-Lopez, Lopez-Cevallos, Cancel-Tirado, Vasquez, 2014), less is known about food pantries themselves. Although many pantries operate in isolation, there are many similarities in what is important to their success in meeting students' need, which are likely generalizable beyond Michigan among the increasing number of US campuses with pantries. The First Annual Michigan College Campuses Food Pantry Summit provided a space to bring campus food pantry staff together to discuss how they address student food insecurity on their respective campuses. The findings show that college campus food pantries are complex systems attempting to address students' food needs. This research is a first step in understanding, documenting, and analyzing how campus pantries are addressing college student food insecurity. This research will, hopefully, improve our understanding of how to address food insecurity among college students and work together to help students achieve academic success by reducing food scarcity.

\section{References}

This article is protected by copyright. All rights reserved. 
Cady, C. L. (2014). Food insecurity as a student issue. Journal of College and Character, 15(4),

$265-272$.

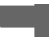

Campbell, R., \& Salem, D. A. (1999). Concept mapping as a feminist research

Imethod. Psychology of Women Quarterly, 23(1), 65-89.

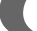

Chaparro, M. P., Zaghloul, S. S., Holck, P., \& Dobbs, J. (2009). Food insecurity prevalence

among college students at the University of Hawai'i at Mānoa. Public Health

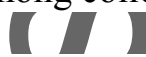

Nutrition, 12(11), 2097-2103.

Coleman-Jensen, A., Rabbitt, M. P., Gregory, C. A., \& Singh, A. (2016, September). Household

food security in the United States in 2015: Economic research report number 215. United

States Department of Agriculture Economic Researcher Services, retrieved from

https!//www.ers.usda.gov/webdocs/publications/err215/err-215.pdf?v=42636

College Board. (2017). Tuition and fees and room and board over time. Trends in Higher

Education, retrieved from https://rends.collegeboard.org/college-pricing/figures-

tables/tuition-fees-room-board-over-time-unweighted

Davies, M.(2011). Concept mapping, mind mapping, and argument mapping: What is the differences and do they matter? Higher Education. 62(3), 279-301.

Dubick, J., Mathews, B., \& Cady, C. (2016, October). Hunger on campus: The challenge of food .

insecurity for college students. A report by College and University Food Bank Alliance,

National Student Campaign Against Hunger and Homelessness, Student Government

Resource Center, and Student Public Interest Research Group, retrieved from

http://studentsagainsthunger.org/wp-content/uploads/2016/10/Hunger_On_Campus.pdf

This article is protected by copyright. All rights reserved. 
Feeding America. (2014). Hunger in America 2014. Technical Report, retrieved from

http://www.feedingamerica.org/hunger-in-america/our-research/hunger-in-america/

Freudenberg, N., Manzo, L., Jones, H., Kwan, A., Tsui, E., \& Gagnon, M. (2011). Food

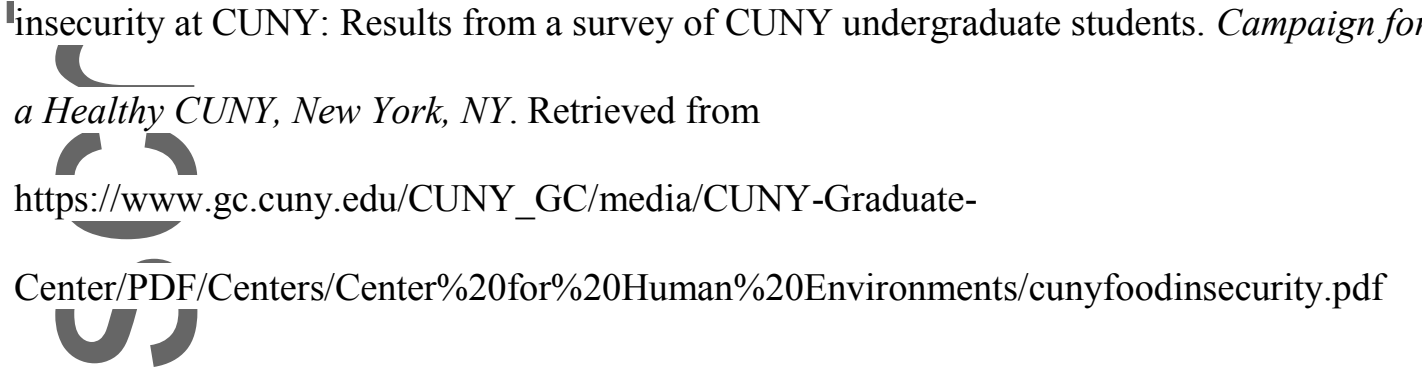

Goldrick-Rab, S., Broton, K., \& Eisenberg, D. (2015, December). Hungry to Learn: Addressing

food and housing insecurity among undergraduates. Wisconsin Hope Lab. Retrieved from

http://wihopelab.com/publications/Wisconsin_HOPE_Lab_Hungry_To_Learn.pdf

Hanbazaza, M., Ball, G. D. C., Farmer, A., Maximova, K., \& Willows, N. D. (2016). Filling a

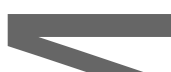

need: Sociodemographic and educational characteristics among student clients of a university food bank. Journal of Hunger and Environmental Nutrition, 11(4), 569-577.

Hinrichs, C., \& Kremer, K. S. (2002). Social inclusion in a Midwest local food system

project. Journal of Poverty, 6(1), 65-90.

Jackson, K. \& Trochim, W. (2002). Concept mapping as an alternative approach for the analysis

of open-ended survey responses. Organizational Research Methods, 5(4), 307-336.

Jordan, M. (2015, April 7). Colleges launch student food pantries to help low-income students.

This article is protected by copyright. All rights reserved. 
The Wall Street Journal, retrieved from https://www.wsj.com/articles/colleges-launch-foodpantries-to-help-low-income-students-1428408001

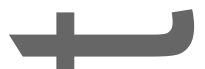

Kane, M., \& Trochim, W. M. (2007). Concept mapping for planning and evaluation. Thousand Oaks, CA: Sage Publications.

Kovacs, K.(2016, November 22). Battling student hunger. Inside Higher Ed, retrieved from

https://www.insidehighered.com/news/2016/11/22/colleges-open-food-banks-battle-student-

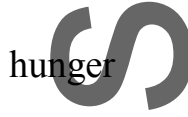

Lindsley, K., \& King, C. (2014). Food insecurity of campus-residing Alaskan college

students. Journal of the Academy of Nutrition and Dietetics, 114(9), A94.

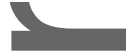

Martinez, S. M., Maynard, K., \& Ritchie, L. D. (2016). University of California Global food Initiative: Student Food Access and Security Study. Retrieved from http://regents.universityofcalifornia.edu/regmeet/july16/e1attach.pdf

Maroto, M. E., Snelling, A., \& Linck, H. (2015). Food insecurity among community college

students: Prevalence and association with grade point average. Community College Journal of Research and Practice, 39(6), 515-526.

Mathewson, T. G. (2017, January 23). Cost of college meal plans getting tougher to swallow.

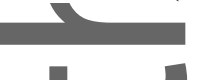

Diverse Issues in Higher Education, retrieved from http://diverseeducation.com/article/91606/

McIntyre, L., Pow, J., \& Emery, J. H. (2015). A path analysis of recurrently food-insecure

Canadians discerns employment, income, and negative health effects. Journal of Poverty, 19(1), 71-87.

This article is protected by copyright. All rights reserved. 
Mitchell, M., Leachman, M., \& Lasterson, K. (2016, August 15). State cuts to higher education threaten quality and affordability at public colleges. Center on Budget and Policy Priorities, retrieved from http://www.cbpp.org/research/state-budget-and-tax/funding-down-tuition-up

Patton-López, M. M., López-Cevallos, D. F., Cancel-Tirado, D. I., \& Vazquez, L. (2014).

Prevalence and correlates of food insecurity among students attending a midsize rural university in Oregon. Journal of Nutrition Education and Behavior, 46, 209-214.

Sampson, N., A1-Khshali, A., Reppond, H. A., Price, C., \& Thomas-Brown, K. (2017). Campus

Pantries Feeding Students: A Report from the 2016 Michigan College Campuses Food Pantry

Summit. Dearborn, MI: CUP Research Team Report.

Saul, S. (2016, June 22). Food pantries address growing hunger problem at colleges. New York

Times, retrieved from https://www.nytimes.com/2016/06/23/education/food-pantries-addressa-growing-hunger-problem-at-colleges.html?_r=0

Saul, S. (2015, December 5). Meal plan costs tick upward as students pay for more than food.

York Times, retrieved from https://www.nytimes.com/2015/12/06/us/meal-plan-costs-

tick-upward-as-students-pay-for-more-than-food.html?_r=1

Seligman, H. (2016, January 24). Food insecurity, health, and health care. Technical Report for

University of California San Francisco, Department of Medicine Center for Vulnerable Populations retrieved from https://cvp.ucsf.edu/resources/Seligman_Issues_Brief_1.24.16.pdf

Tanner, K. (2015, September 12). Which states are among the highest for food insecurity?

Detroit Free Press. Retrieved from http://www.freep.com/story/opinion/contributors/raw-

This article is protected by copyright. All rights reserved. 
data/2015/09/11/michigans-food-insecurity-rate-continues-fall/72019156/

The Concept System ${ }^{\circledR}$ Global MAXTM (Build 2013.322.11) [Web-based Platform]. (2017).

Ithaca, NY. Available from http://www.conceptsystemsglobal.com

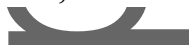

Twill, S. E., Bergdahl, J., \& Fensler, R. (2016). Partnering to build a pantry: A university campus

responds to student food insecurity. Journal of Poverty, 20(3), 340-358.

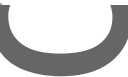

United States Department of Agriculture Economic Research Service. (2016, October 4).

Definitions of food security, retrieved from https://www.ers.usda.gov/topics/food-nutritionassistance/food-security-in-the-us/definitions-of-food-security.aspx

United States Department of Education. (n.d.). Federal Pell Grants are usually awarded only to undergraduate students. Office of Federal Student Aid, retrieved from https://studentaid.ed.gov/sa/types/grants-scholarships/pell

van der Horst, H., Pascucci, S., \& Bol, W. (2014). The "dark side" of food banks? Exploring emotional responses of food bank receivers in the Netherlands. British Food Journal, 116(9), $1506-1520$.

Wheeldon, J, \& Faubert, J. (2009). Framing experiences: Concept maps, mind maps, and data collection in qualitative research. International Journal of Qualitative Methods, 8(3), 68- 83.

Windsor, L.(2013). Using concept mapping in community-based participatory research: A mixed methods approach. Journal of Mixed Methods Research, 7(3), 274-293.

Table 1. Demographic and Campus' Food Pantry Information

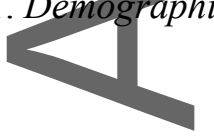

$n \quad$ percent

This article is protected by copyright. All rights reserved. 
Sex

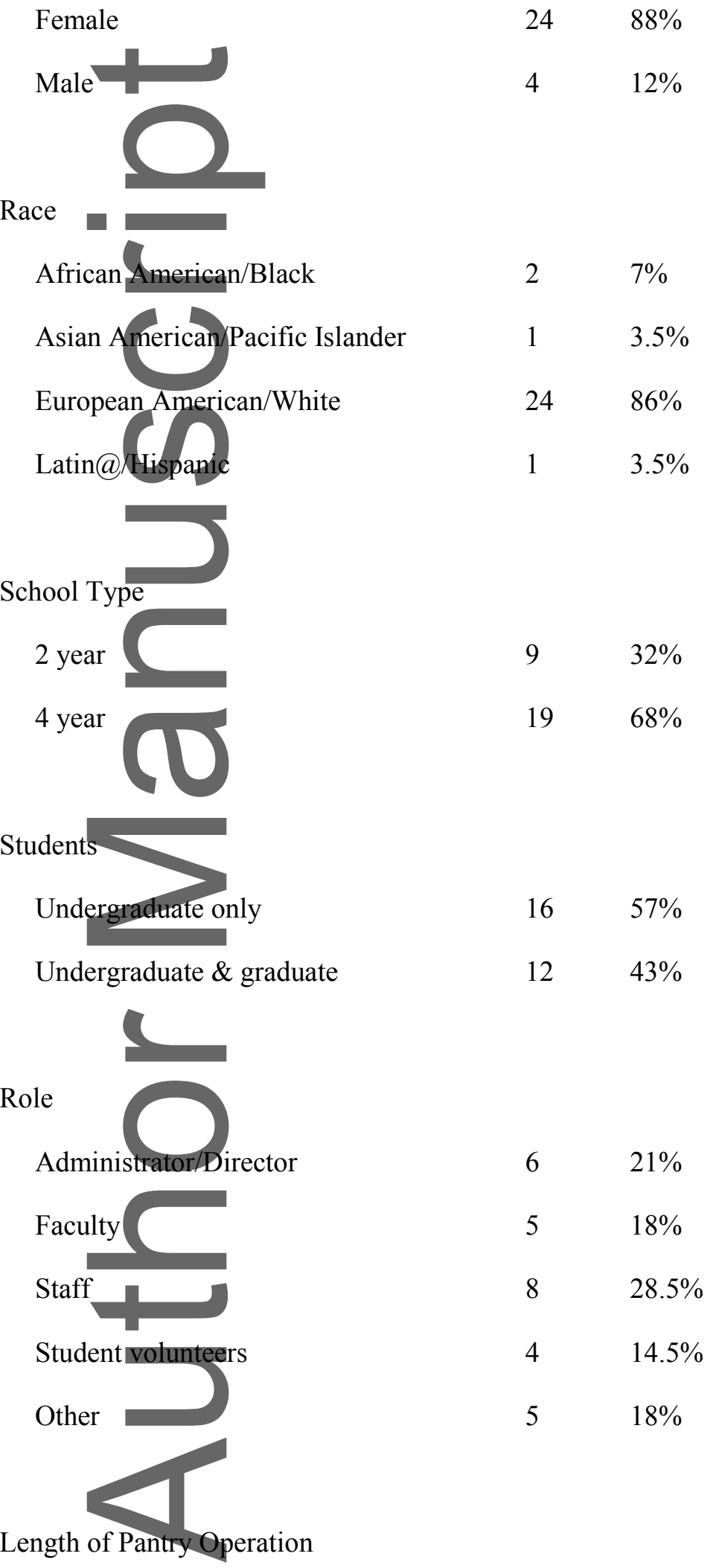

This article is protected by copyright. All rights reserved. 

0-11 months
9
$32 \%$
1-3 years
$12 \quad 33 \%$
4-6 years
$3 \quad 11 \%$
$6+$ years
$4 \quad 14 \%$
Length of time working at the pantry

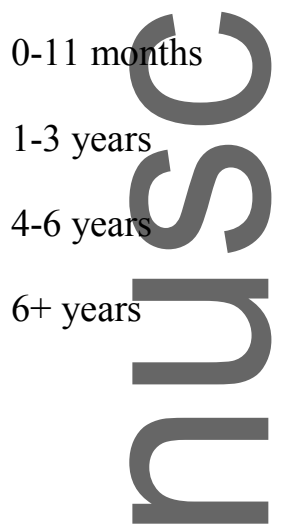
$14 \quad 50 \%$
$11 \quad 39 \%$
$2 \quad 7 \%$
$14 \%$

Table 2. Clusters and Related Statements

\section{Cluster 1: Accessibility}

Statements $(n=21)$

1. We do not ask our students to provide any type of financial "evidence" as to their need.

5. Students can use the pantry $2 x$ per month.

8. I don't know yet. Right now we're serving dinner to sjust a few students twice a week.

10. We open Monday - Friday with a good amount of hours each day so there is a lot of availability for them.

16. We treat students with respect with a "no questions asked" approach other than verifying student status and basic assessment questions.

19. We create a wetcoming and comfortable space.

23. We are located in a building on campus where there is not a lot of student traffic so it is discreet.

26. They can come each week and get food so they have food every week.

31. Our pantry best serves our students by: -providing free food twice a month as long as they are registered in classes

This article is protected by copyright. All rights reserved. 
33. We provide supplemental food assistance to any qualifying students (enrolled in courses without a meal plan) bi weekly.

38. We make services available to eligible students to use the pantry.

45. Students are allowed 4 "lunch bags" \&/or 4 large. bags per month.

53. The pantry is confidential and respectful.

71. Lunch bags the students receive contain 4 items (protein bar or microwaveable can of food, fruit cup or fresh fruit voucher redeemable at on-campus cafe and snack item).

77. We are vorking on measures to make the intake form electronic, "hassle-free" and connected to our student information database.

\section{Offers holiday baskets.}

86. We do our best to keep their anonymity and respect the fact that they do not want others to be aware of their need.

87. We serye over a hundred and fifty families that have used our resource.

89. Some food bags students receive include a take home meal which rotates from every week.

110. Making our students feel welcome and unjudged

112. Provides food twice a month to students who visit the pantry.

\section{Cluster 2: Available Items}

Statements $(n=15)$

21. Provide necessary hygiene supplies to students in need

28. Provide basic food necessities

30. We offer food they can eat while on campus so they can focus on school not their hunger during class

34. Allow students access to healthy food--it is too expensive in stores for college students to afford (1)

43. We want to provide options for everyone

52. We provide students with resources in addition to food such as personal hygiene items and kitchen items

61. Be a security net

63. We dream that our pantry will serve both undergrad and grad students

This article is protected by copyright. All rights reserved. 
67. Provides healthy foods

83. Provides items beyond food such as household and hygiene items

90. Offers services beyond food

96. We are setting up a pantry as part of a broader project on student needs

99. Our goal is to provide as many students as possible with a variety of food items with an increased emphasis on fresh fruits and vegetables

101. Provide healthy alternatives to what students can afford to buy

106. Ensure that all students have their basic needs met

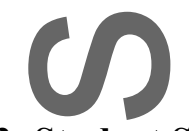

Cluster 3: Student Success

Statements $(n=25)$

9. Help international students feel supported by the school

13. It's more than just about academics regarding the lives of students

24. I hope the pantry will assist students in meeting their basic needs as part of a larger program focusing on non aeademic needs such as homelessness, food insecurity, accessing health care, etc

27. Provide support to international students

39. Our goat is to help students stay enrolled and complete their education

40. Remove stress that comes from experiencing food insecurity

41. Not just provide food but provide hope and assistance to help students become self sufficient and reduce stres

44. But want to ensure every student has enough food - food is one of our most basic needs after all in order for students to be academically successful

58. Recognizing that if a student is not eating they are more than likely in the category of precariously housed or homeless

62. I feel students can not be successful academically to their full ability if they have to worry about where their next meal is coming from

69. We aim to highlight and address food insecurity as one of the many stressors that could potentially hinder our student's success

73. We consider other barriers students may face that interfere with academic success

This article is protected by copyright. All rights reserved. 
75. Make one of the many bills students have to pay smaller, even if just by a small amount

76. Food security $=$ better health and wellness, both physical and mental

84. Provide a peace of mind to students struggling to feed themselves and their families

92. We provide options that will help our students relieve stress from different angles of their life

94. We dream to end student hunger and student anxiety about hunger

95. We dream to give students a greater ability to attend class and other college meetings, events and activities that are critical to maximizing the university experience

98. We dream to improve student health

100. Students appreciate the realization that they have unmet needs and that we are responsive to the challenges they face

102. We want to serve students who are in need without stigmatizing them and understand their barriers to fresh, healthy sustainable food

103. By providing food to students to fill their stomachs to promote academic success

104. We attempt to meet students' unmet hunger needs so they can be effective in their academic endeavors

109. Has provided students some peace of mind around where they can get healthy food

113. Exploring the masking effect of student loans

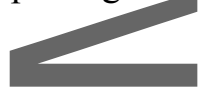

Cluster 4: Support

Statements $(n=21)$

2. We are working on expanding this resource to add to other available opportunities on campus that will help our college promote student success.

12. Doing food demonstrations to teach healthy eating

14. Provide nutrition education and cooking demonstrations.

rar

22. assist them with individual budgeting and independent living skills

29. Hope to provide financial literacy workshops

32. Have the ability to help students apply for SNAP

36. We dream to offer peer mentoring to have an open dialogue within our student body without the presence of faculty/staff/administrators

This article is protected by copyright. All rights reserved. 
37. Give space for new student connections, groups, community?

48. Providing other resources such as nutrition help

51. We atso have numerous food drives throughout the year

54. Provide information about other community resources.

56. Many faculty have incentives for their students to bring food into the food drives.

64. Provide nutrition education

68. We dream to start a food pantry

70. We recruit and gather from internal and external resources to better provide for our students.

78. Food bags include a list of programs and resources to help them get back on track, academically and emotionally.

79. Potential to provide nutrition education

80. We dream to offer individualized personalized plans for our students to give them more than just access to food.

93. Not only supports students but can also aid faculty and staff

105. By creating a unified campus culture of giving through meeting unmet needs.

108. We offer referral services to community based agencies to assist with any other problems that the student may be faeing

\section{Cluster 5: Partnerships}

\section{Statements $(n=12)$}

17. We dream that our pantry will partner with Michigan Department of Health and Human Services to offer more efficient paperwork processing for Women Infant and Children/Supplemental Nutritional Assistance Program/Food Stamp assistance

18. Faculty, staff, administrators, alumni, families, etc. willingly donate with no questions about where their donations are going or how they're being used.

20. Create a community service project for students that don't need access to a food pantry

35. Empower students to support their peers by giving and volunteering.

47. Increase-in-kind support to the pantry on campus

49. I hope we can combat this problem by creating long-term sustainability.

This article is protected by copyright. All rights reserved. 
57. Increase community outreach work towards sustainability

65. We create community partnerships to ensure sustainability.

66. Student organizations and the Greek community have found this a worthwhile project to devote their volunteer hours and fund raising efforts. The student to student engagement has had a positive impact on our campus.

88. As a newer initiative we are still working on assessment practices to determine how we are impacting student retention and progress to degree completion.

91. Develop partnerships with community resources

111. We dream to partner with universities across MI to start a statewide initiative to remove barriers for our studen

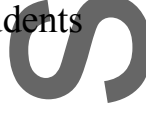

\section{Cluster 6: Awareness}

\section{Statements $(n=19)$}

3. Increase awareness about the pantry among faculty and staff

4. Create a culture of care at the university where we don't hide from challenges but face them together.

6. Provide information and resources about food insecurity Gain awareness around the issue

7. Creates a culture of caring that resonates with the campus community, parents and families, alumni and donors.

11. Faculty and staff are impacted as well

15. We are mindful of the stigma this comes along with being hungry.

25. We dream to raise awareness about food insecurity across campus and within our community

42. Create visibility of a problem that a lot of people don't know exists

46. Created an on campus dialogue about invisible barriers students face to college success.

50. We have further work to do to continue publicizing this to our students.

55. Has started a conversation on campus about this invisible needs which has expanded to talk about other needs such as housing, transportation, childcare etc.

59. We dream to improve the understanding of barriers that students face when attempting to attain a college education.

60. I feel that raising awareness is one of the greatest needs of a food pantry.

This article is protected by copyright. All rights reserved. 
72. help communicate that we care about our students as people and recognize that struggles are something they may experience and that its ok to ask for help.

74. Working to decrease stigma.

81. Once awareness is of pantry services are accomplished, serving the community at large is less of a challenge.

85. Reduce stigma surrounding asking for help

97. Connecting food insecurity to economic insecurity

107. At this time, our students learn about the limited pantry services through LCC employees and other students.

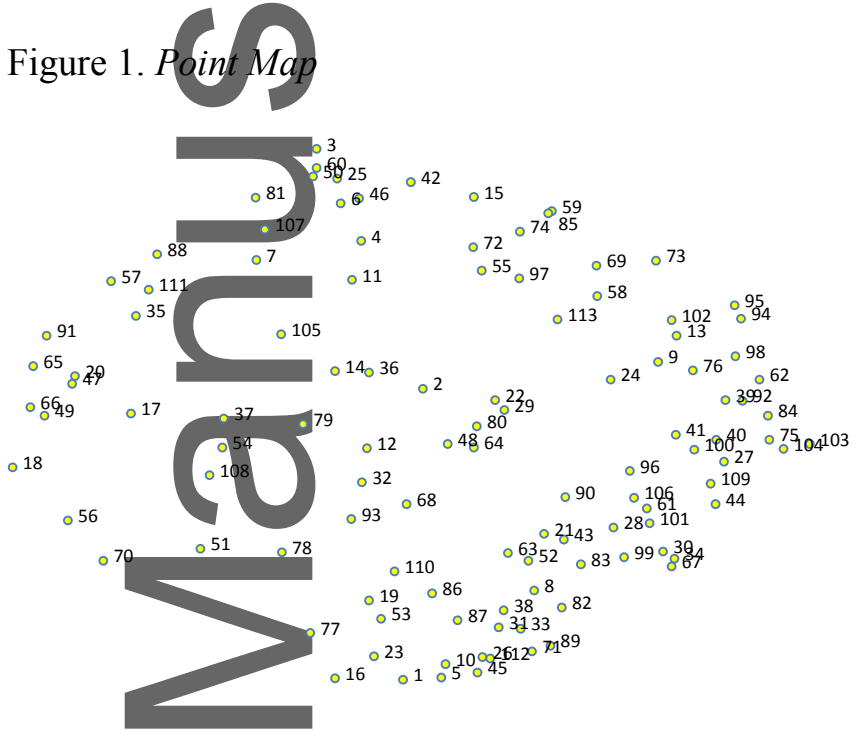

Figure 2. Cluster Map

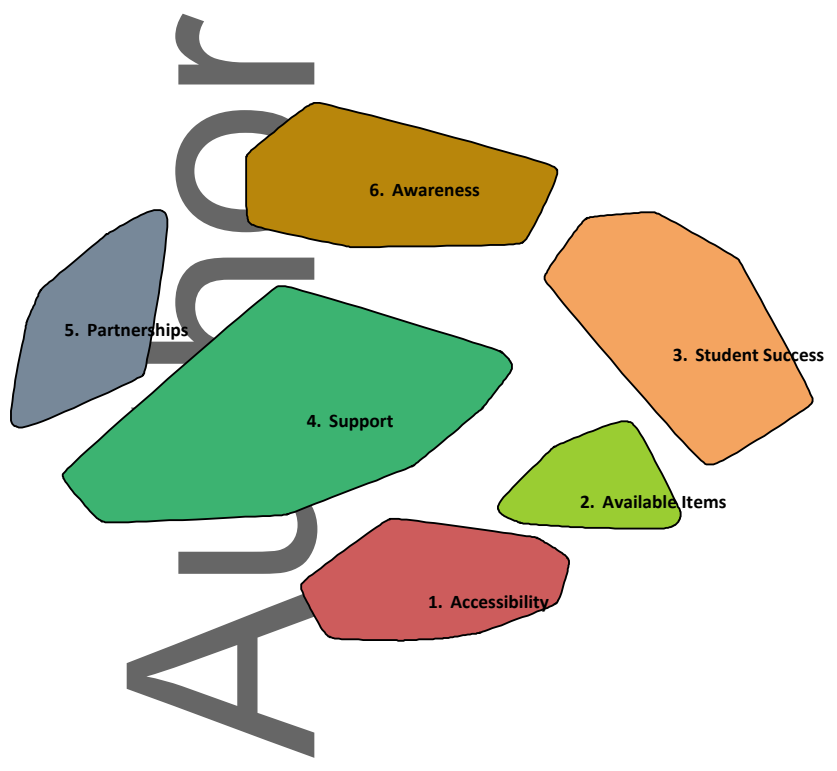

This article is protected by copyright. All rights reserved. 


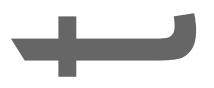

Figure 3. Cluster-Rating Map by Importance

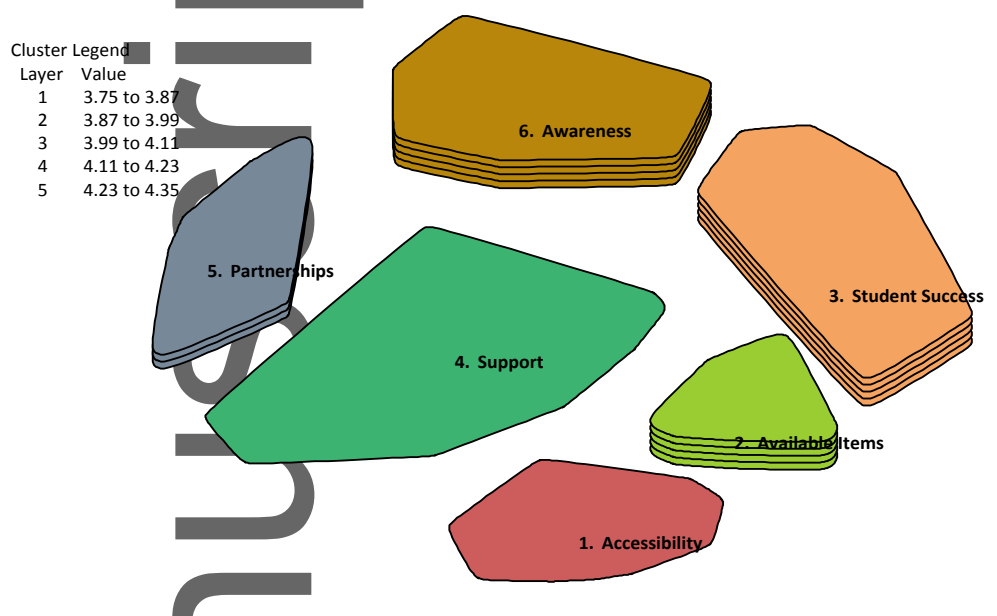

Figure 4. Pattern Match by School Type

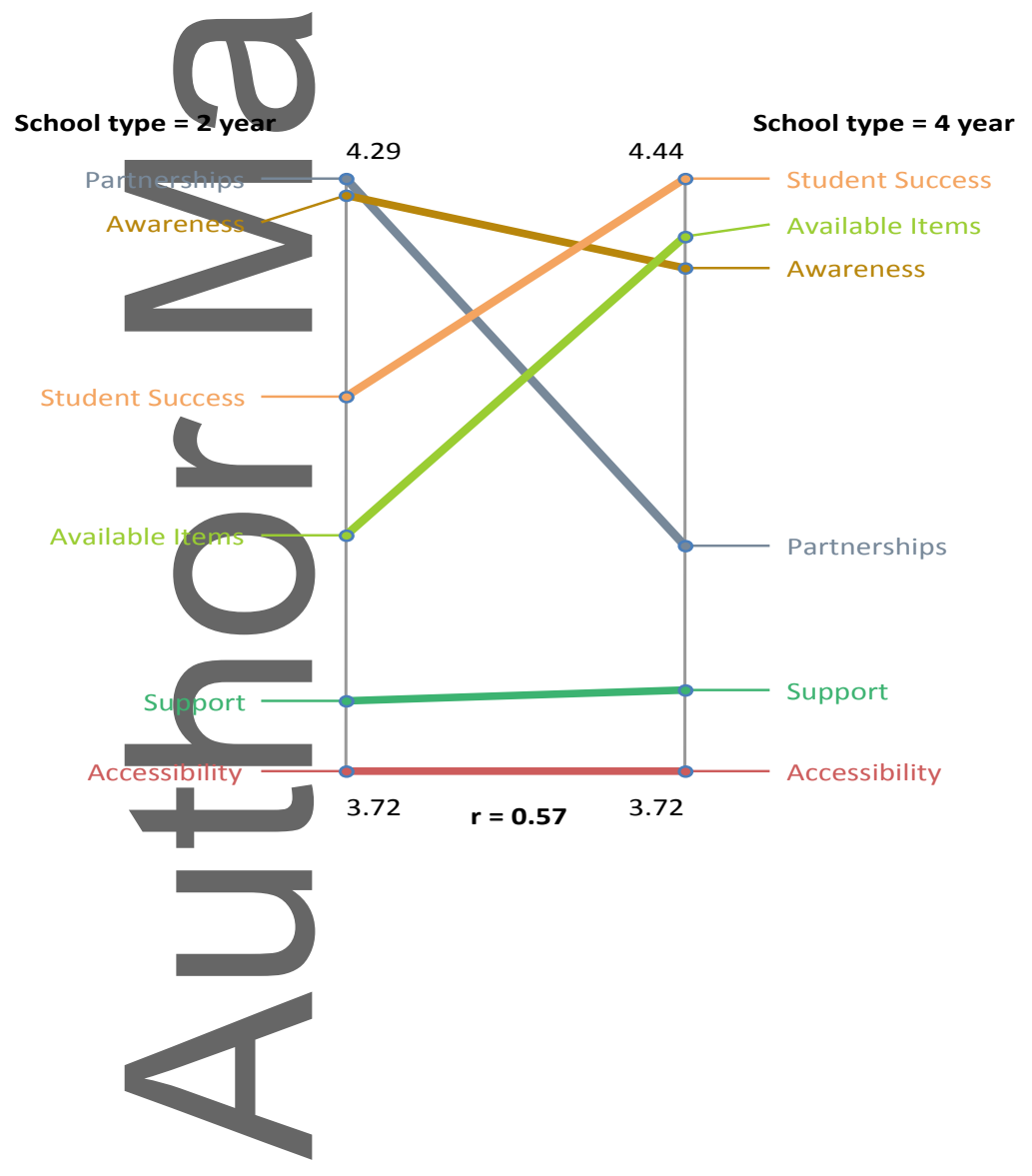

This article is protected by copyright. All rights reserved. 
Figure 5. Pattern Match by Length of Pantry Operation

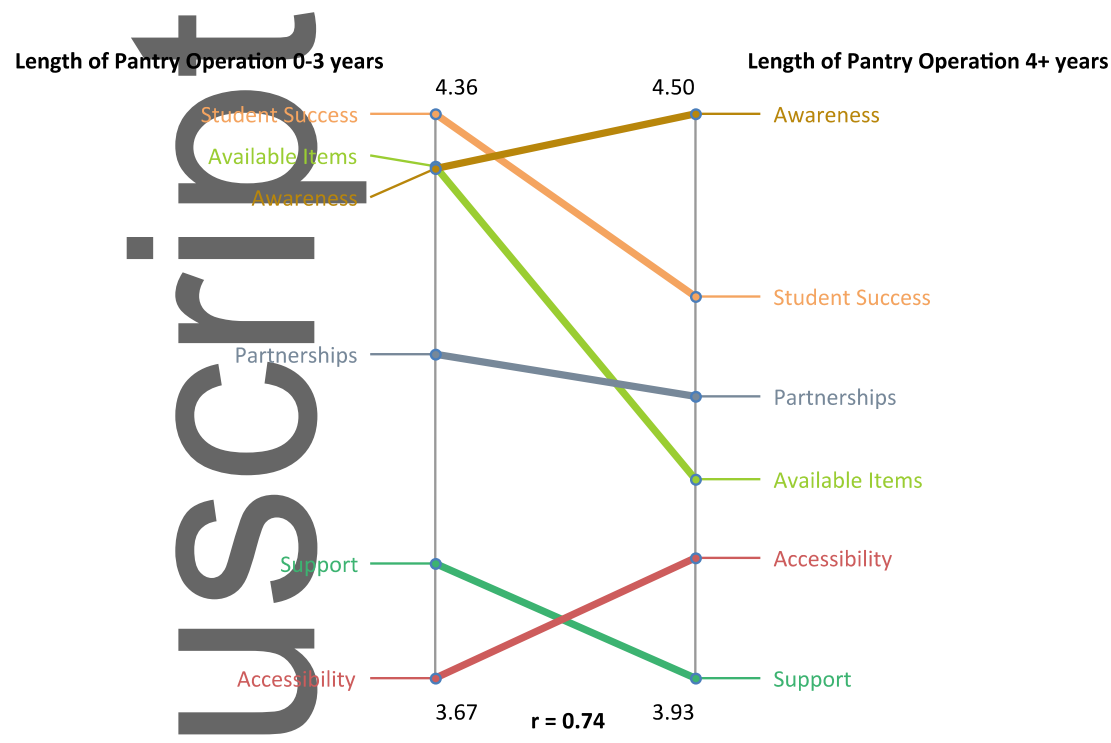

Figure 6. Pattern Match by Type of Students Served

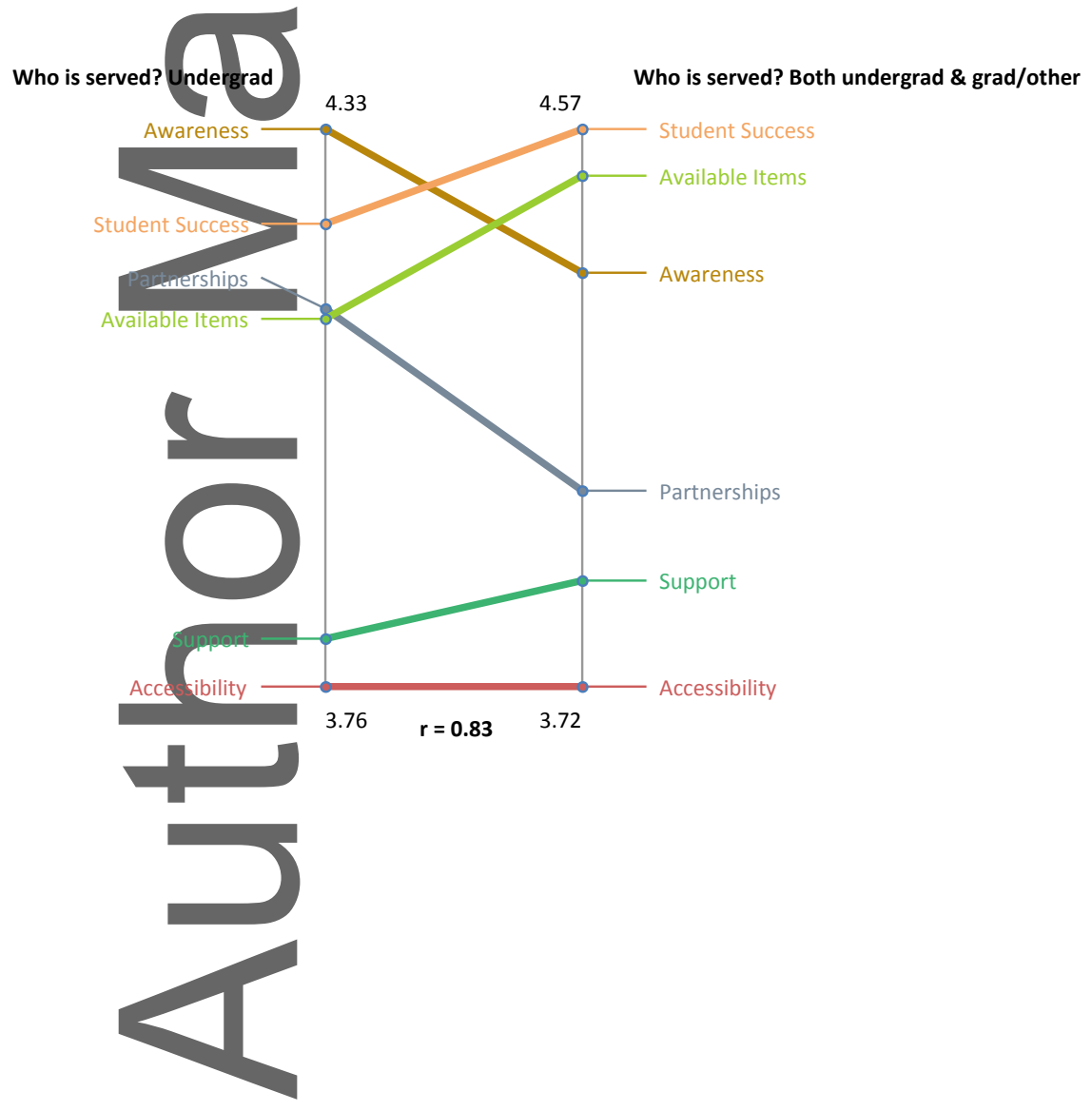

This article is protected by copyright. All rights reserved. 